\title{
Addition of nectar sources affects a parasitoid community without improving pest suppression
}

\author{
Jacob H. Miall, ${ }^{1}$ (D) Paul K. Abram ${ }^{3} \cdot$ Naomi Cappuccino $^{1} \cdot$ Andrew M. R. Bennett $^{2} \cdot$ José L. Fernández-Triana $^{2}$. \\ Gary A. P. Gibson ${ }^{4}$. Peter G. Mason ${ }^{2}$
}

Received: 21 February 2020 / Revised: 3 August 2020 / Accepted: 21 August 2020 / Published online: 9 September 2020

(c) Her Majesty the Queen in Right of Canada, as represented by the Minister of Agriculture and Agri-Food Canada 2020, corrected publication [2020]

\begin{abstract}
A life-table approach was used to test the effect of adding flowering buckwheat to leek plots on mortality and estimated population growth of the invasive leek moth, Acrolepiopsis assectella. This approach was used to estimate the benefits of nectar provisioning on multiple members of the leek moth's parasitoid complex, and the impact of parasitism on the pest's predicted population growth rate. Addition of buckwheat to leek plots shifted the relative abundance of different larval and pupal parasitoid species but did not increase or decrease parasitism levels or their population-level impact on the leek moth. The life-table analysis demonstrated that parasitoids reduced the estimated population growth rate of the leek moth by up to $72 \%$, which far exceeds similar estimates from its native range. Parasitoids found to contribute to leek moth mortality were Itoplectis conquisitor, Conura albifrons and the biological control agent Diadromus pulchellus. In addition, Gambrus ultimus, Scambus calobatus, and Habrobracon sp. are reported here developing on A. assectella for the first time. This study reinforces the hypothesis that the addition of nectar resources to agricultural systems may not have straightforward positive effects and can favour some natural enemies over others, but may not have any overall impact on pest suppression.
\end{abstract}

Keywords Conservation biological control $\cdot$ Diadromus pulchellus $\cdot$ Facultative hyperparasitism $\cdot$ Life tables $\cdot$ Floral resources

Communicated by V. Gagic.

The original online version of this article was revised: In the original article published, the copyright line is incorrect. The correct copyright line of the article is Her Majesty the Queen in Right of Canada, as represented by the Minister of Agriculture and Agri-Food Canada.

Electronic supplementary material The online version of this article (https://doi.org/10.1007/s10340-020-01274-y) contains supplementary material, which is available to authorized users.

Jacob H. Miall

jacob.miall@canada.ca

1 Department of Biology, Carleton University, 1125 Colonel By Drive, Ottawa, ON K1S 5B6, Canada

2 Agriculture and Agri-Food Canada, Ottawa Research and Development Centre, 960 Carling Avenue, Ottawa, ON K1A 06C, Canada

3 Agriculture and Agri-Food Canada, Agassiz Research and Development Centre, 6947 Highway 7, Agassiz, BC V0M 1A0, Canada

4 Honorary Research Associate, Agriculture and Agri-Food Canada, Ottawa Research and Development Centre, 960 Carling Avenue, Ottawa, ON K1A 06C, Canada

\section{Key Message}

- In North America, the invasive leek moth (Acrolepiopsis assectella) is attacked by indigenous parasitoids and an introduced biological control agent.

- A life-table study measured the effects of nectar-provisioning on mortality and parasitism of leek moth in the field.

- Overall, parasitism significantly reduced leek moth populations.

- Adding flowering buckwheat shifted the relative abundance of larval and pupal parasitoid species, but leek moth population growth was not affected.

- Addition of nectar sources may affect natural enemy communities without improving pest suppression. 


\section{Introduction}

Increased plant diversity often increases the species richness and abundance of beneficial insects, including natural enemies, in the field (Poveda et al. 2008; Langellotto and Denno 2004; Berndt et al. 2006; Letourneau et al. 2011). Several hypotheses may explain how this increased plant diversity can lead to improved pest control through trapcropping, natural enemy recruitment, resource subsidies, and masking the attractiveness of the host plant to the pest (e.g., Root 1973; Vandermeer 1989; Heimpel and Jervis 2005). Conservation biological control strategies, including the addition of nectar resources to agricultural systems, can provide refuges and supplementary sugar sources for natural enemies, sometimes leading to improved pest suppression and reduced crop damage (Wratten et al. 2000; Poveda et al. 2008; Tscharntke et al. 2016; Zemenick et al. 2019). However, there is very little evidence to support the hypothesis that increased natural enemy abundance in resource-subsidised systems leads to population-level pest suppression (Cardinale et al. 2003; Weibull et al. 2003).

Addition of floral resources may improve biological control by specific agents through niche separation, by providing potential competitors with a variety of habitats and food sources within an agricultural system (Pedersen and Mills 2004). It can also cause shifts in the composition of the natural enemy complex (Baggen and Gurr 1998; Tscharntke et al. 2007). For example, higher relative abundance of generalist natural enemies that can also act as hyperparasitoids, competitors, and/or intraguild predators of biocontrol agents (Araj et al. 2009; Jonsson et al. 2009; Stephens et al. 1998) could in turn cause an increase in pest densities. It is important to consider the full range of consequences before implementing a conservation biological control strategy, as added effort to support functionally redundant or counterproductive natural enemies may cause these strategies to reduce overall crop yield where arable land is used for intercropping or companion planting in place of crop production (Tscharntke et al. 2005; Letourneau et al. 2011).

Along with determining which companion plant species will provide the most benefit to a natural enemy assemblage in a given system, evaluating the population-level impact of natural enemies in a cropping system is an important step towards implementing an effective conservation biological control strategy, which can be challenging. One method of measuring the impact of natural enemies on a system is a life-table approach, which estimates stage-specific mortality levels and generational reproductive output of a pest (Bellows et al. 1992). Life tables can assist pest management programs by providing insight into which factors are the most important in reducing pest population growth, what life stages they impact and, by extension, which life stages should be targeted when evaluating a candidate biological control agent to supplement a natural enemy community. In some cases, the goal of the life-table analysis may be to evaluate the impact of a single natural enemy or a specific group of natural enemies such as parasitoids (Harcourt 1969; Bellows et al. 1992; Haye et al. 2010; Jenner et al. 2010; Yu et al. 2013). The information gained from a life-table analysis can help to determine the stage-specific impacts of conservation biological control strategies on a particular parasitoid species or guild, and to refine further how to manipulate habitat to maximise pest suppression in an agricultural system. However, to our knowledge, life tables have not previously been used to evaluate the population-level impact of conservation biological control on insect pests.

The leek moth, Acrolepiopsis assectella (Zeller) (Lepidoptera: Glyphipterigidae), was first discovered in North America near Ottawa, Ontario, Canada, in 1993 (Landry, 2007). Since then, it has spread throughout much of eastern Canada and parts of New York and Vermont in the USA (Landry 2007; Mason et al. 2010; Mason et al. 2013a, b; Seto and Shelton, 2016). Native to the Palaearctic (Europe and Asia), this pest of Allium spp. plants can cause heavy economic losses and has induced trade restrictions on commercial Allium crops (Jenner et al. 2010). Diadromus pulchellus (Wesmael) (Hymenoptera: Ichneumonidae) is a solitary pupal endoparasitoid, native to Europe, that has been released against leek moth in Ontario, Canada since 2010 as part of an integrated pest management strategy (Mason et al. 2013a, b).

Prior to and following the reported successful overwintering of D. pulchellus (Mason et al. 2013a, b), a native natural enemy, Conura albifrons (Walsh) (Hymenoptera: Chalcididae) was also found to be associated with the leek moth (Mason et al. 2013a, b; Miall et al. 2014, 2019). This species has become a research focus due to its potential to limit the impact of $D$. pulchellus when post-release monitoring determined that it was increasingly prevalent in fieldcollected leek moth pupae (Mason et al. 2013a, b). Conura albifrons is a facultative hyperparasitoid known to exploit the pupal stage of numerous insect hosts across several different orders (Peck 1963; Hansen 1980), including D. pulchellus (as a hyperparasitoid) and A. assectella (as a primary parasitoid) (Miall et al. 2014). However, it is not yet clear if it demonstrates a distinct behavioural preference for one host or the other. A conservation biological control approach could potentially help to recruit and enhance the impact of introduced and indigenous parasitoids such as D. pulchellus and $C$. albifrons, increasing leek moth mortality rates and decreasing population growth. Improved levels of parasitism were observed when flowering buckwheat, Fagopyrum esculentum Moench (Polygonaceae), which has floral nectar, 
and common vetch, Vicia sativa $\mathrm{L}$. (Fabaceae), which has extrafloral nectar, were provided to both $D$. pulchellus and $C$. albifrons prior to and during exposures to leek moth pupae in a greenhouse cage experiment (Miall et al. 2019). These results are encouraging from a conservation biological perspective; however, it is important to consider that an increase in leek moth mortality due to improved $D$. pulchellus parasitism could be offset if the food web is affected in such a way that $C$. albifrons acts principally as a hyperparasitoid of the biocontrol agent rather than as a primary parasitoid of the pest.

In this study, we tested how the addition of flowering buckwheat, $F$. esculentum, to leek, Allium ampeloprasum L. var. porrum "Hannibal" (Amaryllidaceae), plots affected leek moth mortality and estimated generational reproductive output compared to no-buckwheat plots. We hypothesised that adding floral resources (buckwheat) to leek plots would improve biological control efficacy by providing beneficial nectar resources and shelter to a normally sugar-deprived system. We predicted that all else being equal (i.e., the addition of buckwheat does not disproportionately benefit hyperparasitoids), total leek moth mortality caused by natural enemies, including parasitoids, should be higher when buckwheat is added to standard leek plots and that the buckwheat plots would have increased parasitoid species diversity. We also predicted that if the benefits of floral resource provision vary by natural enemy species, parasitoid species composition or relative abundance would differ between plots with buckwheat versus no-buckwheat plots.

\section{Materials and methods}

\section{Leek moth culture}

The leek moth culture for these experiments was maintained using methods described by Miall et al. (2019) and housed in a climate-controlled rearing room at $25 \pm 1{ }^{\circ} \mathrm{C}$ on a $16 \mathrm{~L}: 8 \mathrm{D}$ light cycle and $50 \pm 10 \%$ relative humidity $(\mathrm{RH})$.

\section{Host plant maintenance}

Leek seeds were sown into 48 -cell flats $(25 \times 45 \mathrm{~cm})$ and placed in a greenhouse $\left(23 \pm 10^{\circ} \mathrm{C}\right.$ on a $16 \mathrm{~L}: 8 \mathrm{D}$ light cycle and $30 \pm 10 \% \mathrm{RH})$. Once leeks had grown to $20-30 \mathrm{~cm}$ in height (approximately 90 days), seedlings were transplanted individually into $12-\mathrm{cm}$ fibre pots for use in the stage-specific mortality component of the life-table field experiments. The remaining seedlings were kept in their flats for approximately 45 more days until they were transplanted into the field.

\section{Plant selection}

Buckwheat was selected as a companion crop for this study because it has been shown to promote female bias in parasitoid offspring and increase relative abundance and levels of parasitism (Berndt et al. 2006; Lee and Heimpel 2008). Due to its relatively low cost, long flowering season, erosion protection, and adaptability to poor growing conditions, buckwheat is often used as a source of green manure, a crop border or as a companion plant in intercropping systems (Bowie et al. 1995; Possinger et al. 2013). We thus considered it to be a good candidate to provide a consistent, longlasting resource for natural enemies both as a nectar source and as a refuge. It was also seen as having low potential for improving conditions for the study pest as leek moth larvae are very specific to Allium spp. plants.

\section{Field plot}

A two-year life-table study was conducted in a cultivated field $(40 \times 70 \mathrm{~m})$ at the Central Experimental Farm in Ottawa, Ontario Canada $\left(45.3899^{\circ} \mathrm{N}, 75.7141^{\circ} \mathrm{W}\right)$. Four rectangular blocks were set up on the corners of the field, which was tilled continually throughout the growing season to prevent establishment and maturation of unwanted flowering plants. Each $12 \times 25$ m block was prepared with 10 furrowed rows, $1 \mathrm{~m}$ apart, into which greenhouse-grown leeks were planted every $50 \mathrm{~cm}$ (the length of each east-west row). Two of the blocks, designated as "buckwheat," were machine sown with buckwheat seed approximately 1 week prior to the leek plantings beginning in the middle of May of both study years. The other two blocks, designated as "nobuckwheat," consisted of leek plantings only. Any unwanted flowering plants were removed from the buckwheat and nobuckwheat blocks on a weekly basis. In both 2015 and 2016, buckwheat blocks were placed in opposite corners from each other, as were the no-buckwheat blocks, to maximise the spacing between treatments. Buckwheat blocks were alternated between years.

\section{Experimental procedure}

Briefly, the leek moth undergoes three complete generations in eastern North America with the first flight period beginning in mid to late spring with overwintering adults laying eggs on the surface of Allium spp. leaf tissue. Following egg hatching, newly emerged first instar (neonate) larvae mine into the plant tissue and complete five larval instars. When feeding and development is complete, larvae make a silk-woven cocoon on the surface (generally underside) of their host plant leaves and form a sclerotized pupa following final larval moult. To manipulate age and density in all life stages of $A$. assectella, a sentinel-host exposure approach 
was used to evaluate field mortality using individuals from the laboratory-reared colony. For each leek moth life stage (egg, neonate, larva, pupa), two infested leeks were placed in each row within each of the four blocks (=20 infested leeks per block per life stage). In order to provide access to soil surface-dwelling predators, potted leek plants were dug into the ground, so the base of the potted plant was level with the base of the field-grown leeks. The life-table study began when adult leek moth pheromone trap counts indicated the beginning of the second generation, selected for the study due to its relatively high percentage of leek moth parasitism compared to the first and third generations (JHM \& PGM, unpublished data). In addition, the flowering period of the buckwheat used in this experiment corresponded with the timing of the second generation.

\section{Stage-specific mortality}

All sentinel leek moth eggs, larvae, pupae and adults were held in a rearing room under the rearing conditions described above, then transferred to leek plants and placed in the field once they had reached the desired developmental stage. Sentinel setups of each life stage were placed sequentially and synchronised with the phenology of the naturally occurring leek moth population. Sentinel eggs, larvae, and pupae were placed in the field only for the duration of that life stage (with the exception of the egg-neonate stage which was left out in the field for the duration of egg hatching and first instar development), after which they were retrieved and evaluated in the laboratory. In each block, two potted leeks (one "caged" and one "uncaged"; see Natural enemy impact below for rationale) were placed in a randomly assigned location in each leek row, for each life stage (a total of 20 plants per block). The placement within the rows was marked with a flag and utilised for each life stage throughout the experiment. Simultaneously with the experiments, a subset of infested leek plants containing sentinel eggs, larvae, and pupae were placed adjacent to the field site to monitor developmental progression precisely.

Leek moth eggs were obtained by hanging strips of young leek leaves (approximately $2 \times 15 \mathrm{~cm}$ ) from the ceiling of the leek moth oviposition cage overnight (approximately $15 \mathrm{~h}$ ). The next morning, the leaves were removed from the oviposition cages and divided into approximately $2 \mathrm{~cm}$ sections containing 20-40 healthy eggs. Infested leaf sections were then attached to potted leeks from the greenhouse and transferred to the field (one section per plant). Each leaf section was pinned to the ventral side of a strong leaf using insect pins (Black Enameled \#2, BioQuip, Rancho Dominguez, California, USA). Following collection from the field, eggs were placed in Petri dishes $(50 \times 15 \mathrm{~mm}$, Semadeni AG, Ostermundigen, Switzerland) and kept in a rearing room at $22 \pm 1{ }^{\circ} \mathrm{C}$ on a $16 \mathrm{~L}: 8 \mathrm{D}$ light cycle and $50 \pm 10 \% \mathrm{RH}$ to record survival.

Following the same preparation methods as above, a second cohort of 20-40 eggs was pinned to leek plants and placed in the field at the same time as the first cohort. Instead of retrieving eggs prior to hatching, this second cohort was allowed time ( 3 days) to hatch, and for neonates to mine into leek leaves. Following retrieval from the field, infested plants were brought back to the laboratory for dissection to determine the number of first instar larvae that had successfully entered the leek plant tissues.

To measure mortality of the $2-5$ th larval instars, 20 newly hatched $(<2 \mathrm{~h}$ old $)$ first instar leek moth larvae were transferred to freshly cut tips of each potted leek plant, using a fine paint brush. Infested plants were placed in a rearing room $\left(15 \pm 1{ }^{\circ} \mathrm{C}\right.$ on a $16 \mathrm{~L}: 8 \mathrm{D}$ light cycle and $50 \pm 10 \%$ $\mathrm{RH})$ overnight, to allow neonates to enter the plant. The following morning, infested plants were transported to the field and placed into their assigned row and block. Care was taken to ensure that any adjacent leek leaves from nearby plants were trimmed to deter larvae from moving off the experimental plants. Larvae were left in the field for the duration of their development and retrieved just prior to pre-pupal formation on the plant. All retrieved plants were brought back to the laboratory for dissection and evaluation of larval survivorship, mortality and parasitism. Recovered larvae were placed in clear plastic cylinders $(100 \times 53 \mathrm{~mm}$, Semadeni AG, Ostermundigen, Switzerland) with leek sections to record any emergence of parasitoids. Larvae that were visibly parasitised (i.e., had ectoparasitoids present on or near paralyzed leek moth larvae) were placed in capped and labelled 96-well plates (Nunc MaxiSorp flat-bottom, LS44240421 Invitrogen ThermoFisher Scientific, Waltham, Massachusetts, USA) and kept in a rearing room at $22 \pm 1{ }^{\circ} \mathrm{C}$ on a 16L:8D light cycle and $50 \pm 10 \% \mathrm{RH}$ for the duration of parasitoid development.

Mortality in the pupal stage was measured by attaching 10 newly formed $(<12 \mathrm{~h}$ old) leek moth pupae to the ventral side of leaves of potted leek plants. Pupae were obtained by collecting pre-pupae from the leek moth rearing culture and pinning them to a foam pinning block, carefully placing the pin (Black Enameled \#0, BioQuip, Rancho Dominguez, California, USA) between the middle of their pupal casing and silk cocoon (so as not to damage the pupa) into the foam. Pinned pre-pupae were placed in a rearing room $\left(25 \pm 1{ }^{\circ} \mathrm{C}\right.$ on a $16 \mathrm{~L}: 8 \mathrm{D}$ light cycle and $50 \pm 10 \% \mathrm{RH}$ ) overnight to allow for development into pupae. The following morning the newly formed pupae were attached to the plants, which were dug into their assigned row and block in the field. All pupae were recovered and placed into labelled clear plastic dishes $(50 \times 15 \mathrm{~mm})$ just prior to adult emergence and brought back to the laboratory to monitor mortality and adult leek moth or parasitoid emergence. All pupae were kept in 
a rearing room at $22 \pm 1{ }^{\circ} \mathrm{C}$ on a $16 \mathrm{~L}: 8 \mathrm{D}$ light cycle and $50 \pm 10 \%$ RH.

\section{Parasitoid identifications}

All parasitoids reared from leek moth during the study years were retained, mounted and submitted to the Canadian National Collection of Insects, Arachnids and Nematodes (CNC) housed at the Ottawa Research and Development Centre at the Central Experimental Farm in Ottawa, Ontario, Canada. Parasitoids were identified by GAPG (Chalcididae), ARMB (Ichneumonidae) and JFT (Braconidae). Voucher specimens of each species were retained and deposited into the $\mathrm{CNC}$ for future barcoding and permanent historical record.

\section{Natural enemy impact}

An exclusion technique was used to evaluate the effect that predators and parasitoids had on leek moth survivorship. For each life stage, half of the infested plants were covered with a fine-mesh bag $(30 \times 10 \mathrm{~cm}$, DC3210 MegaView Science Co., Ltd., Taiwan) prior to being placed in the field. The bag was placed over the whole plant and cinched at the base of the plant just above the soil surface. These "caged" plants were used to exclude biotic mortality factors that "uncaged" plants were exposed to (i.e., parasitoids, predators). The natural enemy impact was estimated by comparing stagespecific survivorship between the caged and uncaged leeks.

\section{Potential and realised fecundity}

To construct complete life tables for the field experiments, it was necessary to estimate the potential and realised female leek moth fecundity. To determine potential fecundity, a pair of newly emerged male and female leek moths were placed in a Petri dish $(91 \times 20 \mathrm{~mm}$, Semadeni AG, Ostermundigen, Switzerland) with a piece of filter paper lining the bottom, and a 1-cm-long cotton bud soaked with a $10 \%$ sucrose solution. Each pair was also provided with a freshly cut piece of leek leaf (approximately $3 \times 2 \mathrm{~cm}$ ). Oviposition arenas were kept in a rearing room at $22 \pm 1{ }^{\circ} \mathrm{C}$ on a $16 \mathrm{~L}$ :8D light cycle and $50 \pm 10 \%$ RH. Every $2-3$ days, the adult moths were transferred to a clean Petri dish containing a new piece of filter paper, cotton sucrose bud, and leek leaf, and eggs laid in the vacated Petri dishes and on leek leaves were counted and recorded. This process continued for the lifetime of each female leek moth. A total of 19 and 21 leek moth pairs were observed in the laboratory in 2015 and 2016, respectively. Females that did not lay eggs were presumed to be unmated and were excluded from these experiments.

To determine the realised fecundity of leek moths in the field, a pair of newly emerged male and female leek moths were placed on a young, potted leek plant (approximately $20 \mathrm{~cm}$ tall), encased by a windowed, fine-mesh bag $(40 \times 20$ cm, DC3000W-S MegaView Science Co., Ltd., Taiwan), cinched around the rim of the pot. To prevent the mesh bag from collapsing into the leek plant, wire hoops were placed inside the pot and shaped to keep the mesh bag cylindrical. These oviposition plants were placed in the field margins of the study plot at the beginning of the second field generation. Every 3-5 days, the adult moths were transferred to a new potted leek plant, and all eggs laid on the previously exposed plants were counted and recorded. This process continued for the lifetime of each female leek moth. A total of 22 and 18 leek moth pairs were observed in the field in 2015 and 2016, respectively. Females that did not lay eggs were presumed to be unmated and were excluded from these experiments.

\section{Construction of life tables}

Following Jenner et al. (2010) and Haye et al. (2014), and using techniques described by Bellows and Van Driesche (1999), field mortality data were used to construct horizontal, stage-specific life tables for each treatment during the second leek moth generation in 2015 and 2016. Mortality probability was calculated using a known number of leek moth individuals for each life stage; however, to simplify and standardise the presentation of accumulated mortality, a starting number of 1000 eggs was used. Apparent mortality $\left(q_{x}\right)$, caused by known (e.g., parasitism) or unknown abiotic and biotic factors, was determined as the ratio of the number of individuals dying in a stage $\left(d_{x}\right)$ to the number entering the stage $\left(l_{x}\right)$. Real mortality $\left(r_{x}\right)$ was calculated by determining the ratio of individuals dying in a particular stage to the initial starting number at the beginning of the study. The number of individuals entering each life stage was determined by subtracting the number dying in each stage from the number entering the previous stage. Marginal attack rate $\left(m_{x}\right)$ was used to estimate the number of individuals entering a stage that would be attacked by an agent (e.g., parasitoids) if it were acting in the absence of other mortality factors. When overlap between mortality factors occurred, or a specific factor was indistinguishable, the marginal attack rate would be equal to the apparent mortality. Once marginal attack rates for each stage were calculated, $k$-values (level of mortality in a given stage) were determined as - log $\left(1-m_{x}\right)$. Each $k$-value represents the impact of mortality in each stage on the total generational mortality $\left(K_{g}\right)$, which is the sum of the $k$-values. Finally, the net reproductive rate of increase $\left(R_{o}\right)$ was determined by dividing the number of estimated surviving progeny by the initial number of individuals used in the study. This value represents the factor by which a population increases (or decreases) in successive generations (Van Driesche et al. 2009). 


\section{Impact of parasitism}

To evaluate parasitoid impact on leek moth population growth in each year and treatment, we calculated hypothetical differences in net reproductive rate $\left(R_{0}\right)$ when removing leek moth mortality due to parasitism. This allowed an estimation of the percent reduction in leek moth $R_{0}$ due to parasitism.

\section{Statistical analyses}

To assess the effects of floral treatment (buckwheat, nobuckwheat), cage treatment (caged, uncaged), and their interaction on leek moth mortality and parasitism levels, we used generalised linear mixed models (GLMMs) with a binomial error distribution and a logit link function, floral treatment and cage treatment as fixed factors, and field block as a random factor. For both mortality and parasitism response variables, we ran separate GLMMs for each leek moth life stage and year of data. The statistical significance of each model's fixed factors and their interaction were determined with Type II Wald Chi-squared tests (Anova function in the "car" package of R statistical software). To interpret significant treatment/cage treatment interaction effects, we examined the effect of floral treatment separately for each floral treatment using the same GLMM and significance testing procedure as described above.

The effects of floral treatment, year, and their interaction on parasitoid species composition (for plants from which at least one parasitoid was reared) were modelled with permutational multivariate analysis of variance (PERMANOVA; a nonparametric analogue to a traditional MANOVA) with a Euclidian distance matrix (Anderson 2001). The data were organised as counts of the number of each parasitoid species on each plant. Because there was too little parasitism data from caged plants to include cage treatment as a factor in models, data from both cage treatments were pooled for these analyses. Models were run with 1000 permutations, and the assumption of equal multivariate spread was verified in all cases. Separate models were run for each parasitised leek moth life stage (i.e., larvae, pupae).

All analyses were conducted with $\mathrm{R}$ software version 3.3.2 (R Core Team 2016).

\section{Results}

\section{Stage-specific mortality}

There were varying effects of floral treatment (i.e., buckwheat, no-buckwheat) and cage treatment (i.e., caged, uncaged) on leek moth mortality across life stages and years (Fig. 1).
In 2015, floral treatment did not affect leek moth mortality during the egg $\left(\chi^{2}=0.002, \mathrm{df}=1, P=0.96\right)$ or larval $\left(\chi^{2}=0.001, \mathrm{df}=1, P=0.98\right)$ stage. For neonates, the effect of floral treatment depended on cage treatment $\left(\chi^{2}=4.09, \mathrm{df}=1, P=0.043\right)$ : in the uncaged treatment, neonate mortality tended to be lower in plots with buckwheat $\left(\chi^{2}=23.88, \mathrm{df}=1, P<0.0001\right)$, whereas there was no effect of buckwheat on neonate mortality in the caged treatment $\left(\chi^{2}=0.31, \mathrm{df}=1, P=0.58\right)$ (Fig. 1). In the uncaged treatment, there was $100 \%$ pupal mortality in both the buckwheat and the no-buckwheat treatments. In the caged treatment, pupal mortality was similar in plots with and without buckwheat $\left(\chi^{2}=0.17, \mathrm{df}=1, P=0.68\right)$ (Fig. 1). Mortality of eggs $\left(\chi^{2}=42.54, \mathrm{df}=1, P<0.0001\right)$, larvae $\left(\chi^{2}=103.53, \mathrm{df}=1\right.$, $P<0.0001$ ), and pupae (complete mortality in uncaged treatment) was lower on caged plants than on uncaged plants (Fig. 1). Neonate mortality was higher in the caged treatments than in the uncaged treatments $\left(\chi^{2}=37.06, \mathrm{df}=1\right.$, $P<0.0001$ ) (Fig. 1).

In 2016, the buckwheat treatment did not affect leek moth mortality during the egg $\left(\chi^{2}=1.308, \mathrm{df}=1, P=0.25\right)$ and pupal stage $\left(\chi^{2}=0.188, \mathrm{df}=1, P=0.66\right)$. Neonate mortality was lower in the buckwheat plots than in the no-buckwheat plots $\left(\chi^{2}=5.056, \mathrm{df}=1, P<0.05\right)$, whereas larval mortality was higher in the buckwheat plots $\left(\chi^{2}=6.294, \mathrm{df}=1\right.$, $P<0.05)$. In plots with and without buckwheat, neonate mortality was higher in the caged treatment than uncaged treatment $\left(\chi^{2}=4.541, \mathrm{df}=1, P<0.05\right)$. Mortality of eggs $\left(\chi^{2}=11.18, \mathrm{df}=1, P<0.001\right)$, larvae $\left(\chi^{2}=79.63, \mathrm{df}=1\right.$, $P<0.0001)$, and pupae $\left(\chi^{2}=120.96, \mathrm{df}=1, P<0.0001\right)$ was lower on caged plants than on uncaged plants in both the buckwheat and no-buckwheat plots (Fig. 1).

\section{Generational mortality}

The contribution of each life stage of leek moth to its generational mortality and the estimated net reproductive rate for each treatment in 2015 and 2016 is summarised in Table 1 (see Supplementary Tables 1-8 for complete life tables for both years). In all treatments in both years, generational mortality was highest in the pupal stage, except in 2016 for caged, buckwheat and no-buckwheat plots which had highest generational mortality in the neonate stage (Table 1). The second highest generational mortality was seen in the larval stage in all treatments in both years, except for the 2015 caged buckwheat and no-buckwheat plots, in which the neonate stage showed the second highest contribution to generational mortality (Table 1). The third highest contributor to generational mortality occurred in the larval stage in the caged buckwheat and no-buckwheat treatments and as an egg and neonate in the uncaged buckwheat and no-buckwheat treatments, respectively, in 2015. In 2016, the third highest contributor to generational mortality occurred in the 
Fig. 1 Stage-specific mortality $( \pm \mathrm{SE})$ by treatment, of leek moth, Acrolepiopsis assectella, in 2015 and 2016. Caged (C), uncaged $(\mathrm{U})$ treatments in buckwheat (B) and no-buckwheat (NB) blocks. (Asterisks (*) indicate significant differences $[P<0.05]$ between treatments as determined by Type II Wald chi-square tests: $*=$ caged and uncaged treatments; $* *=$ buckwheat and no-buckwheat treatments)
Table 1 Contribution of each leek moth (Acrolepiopsis assectella) life stage towards generational mortality for caged and uncaged, buckwheat and no-buckwheat leek plots in 2015 and 2016

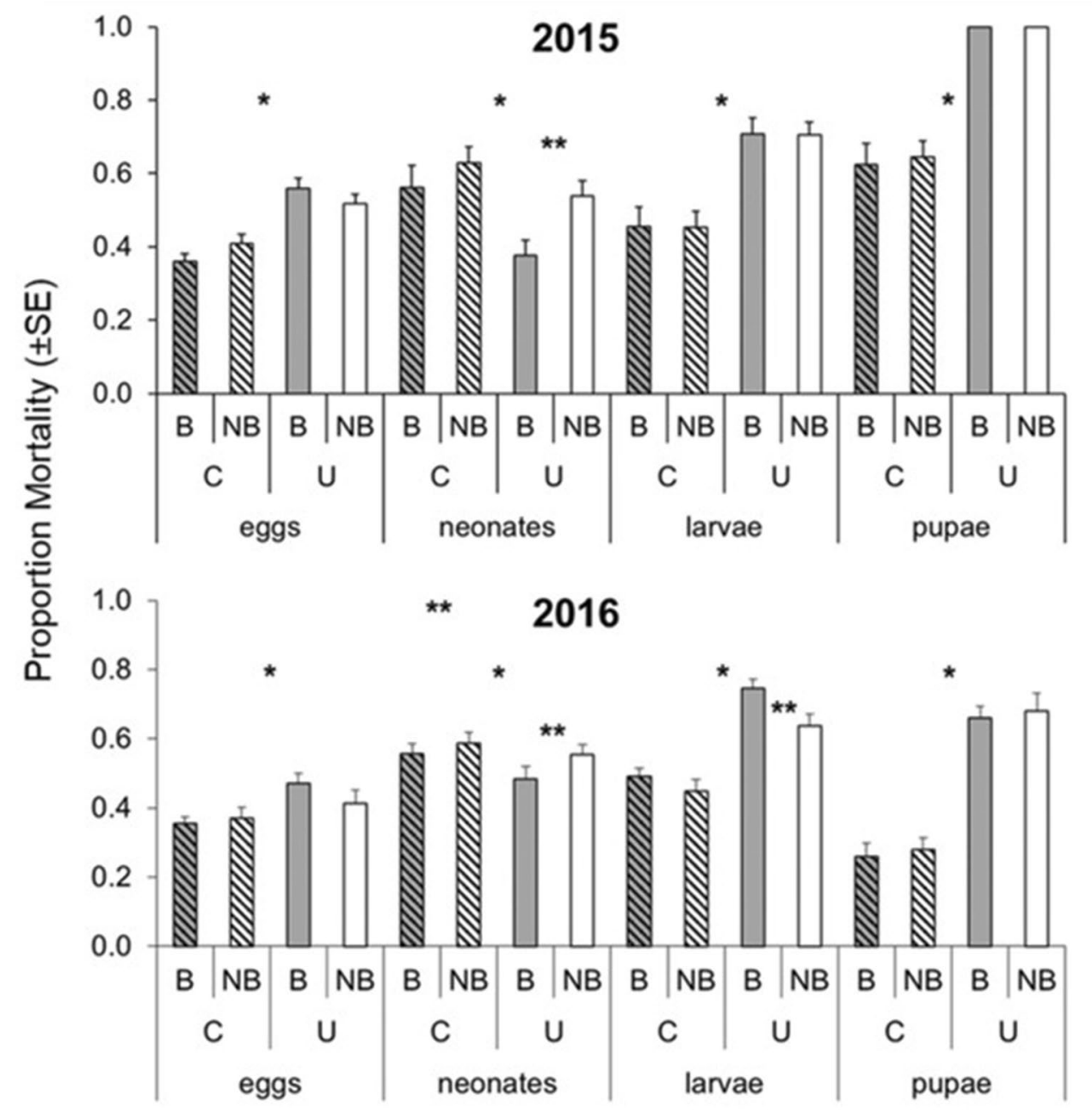

\begin{tabular}{lllllllll}
\hline Year & Treatment & \multicolumn{5}{c}{$\begin{array}{l}\text { \% contribution to generational } \\
\text { mortality }\end{array}$} & $\begin{array}{l}\text { Total genera- } \\
\text { tional mortality } \\
(\%)\end{array}$ & $\begin{array}{l}\text { Net reproduc- } \\
\text { tive rate }\left(R_{0}\right)\end{array}$ \\
\cline { 3 - 6 } & & & & Egg & Neonate & Larval & Pupal & \\
\hline 2015 & \multirow{2}{*}{ Caged } & Buckwheat & 12.3 & 23.8 & 17.0 & 27.5 & 94.4 & 2.92 \\
& & No-buckwheat & 13.3 & 26.2 & 15.7 & 26.9 & 95.7 & 2.21 \\
& \multirow{2}{*}{ Uncaged } & Buckwheat & 19.0 & 10.8 & 28.5 & 41.7 & 100.0 & 0.00 \\
& \multirow{3}{*}{ Caged } & No-buckwheat & 14.9 & 16.0 & 25.3 & 43.9 & 100.0 & 0.00 \\
& \multirow{2}{*}{ Uncaged } & Buckwheat & 15.2 & 27.8 & 23.0 & 10.5 & 89.3 & 5.95 \\
& No-buckwheat & 15.3 & 30.1 & 20.0 & 11.3 & 89.7 & 5.73 \\
& Buckwheat & 11.9 & 12.4 & 25.6 & 37.1 & 99.0 & 0.53 \\
& No-buckwheat & 9.9 & 15.3 & 18.9 & 43.0 & 99.1 & 0.52 \\
\hline
\end{tabular}

Resulting net reproductive rate $\left(R_{0}\right)$ is tabulated for each treatment in 2015 and 2016. Note: contribution to generational mortality by adult sex ratio is not shown in this table. Refer to Supplementary Tables $1-8$ for complete life tables egg stage of the caged buckwheat and no-buckwheat treatments, and in the neonate stage of the uncaged buckwheat and no-buckwheat (Table 1). The highest net reproductive rate occurred in the caged treatments in both years (2015: $\left.R_{0}=2.92 ; 2016: R_{0}=5.95\right)$ while the lowest net reproductive rate occurred in the uncaged treatments in both years 
(2015: $R_{0}=0.00 ; 2016: R_{0}=0.52$ ) (Table 1). Net reproductive rate and generational mortality were qualitatively similar between floral treatments in both years.

\section{Parasitism effects on leek moth mortality}

Mortality due to parasitism was only observed in the larval and pupal stages of $A$. assectella. There was no effect of floral treatment on larval parasitism in $2015\left(\chi^{2}=0.18\right.$, $\mathrm{df}=1, P=0.67)$, but in 2016 on the uncaged plants it was almost twice as high in the buckwheat plots than in the nobuckwheat plots ( $\left.\chi^{2}=8.41, \mathrm{df}=1, P=0.0037\right)$ (Fig. 2). In both years, some pupal and larval parasitism was observed in caged leeks, indicating that parasitoids were, to some degree, able to oviposit through the mesh bags (particularly those species with long and narrow ovipositors that do not require close contact with the host (e.g., C. albifrons and Habrobracon sp.) (Fig. 2). Larval parasitism was higher in the uncaged treatment than the caged treatment in both $2015\left(\chi^{2}=10.85, \mathrm{df}=1, P<0.001\right)$ and $2016\left(\chi^{2}=41.24\right.$, $\mathrm{df}=1, P<0.0001$ ) (Fig. 2). In 2015, the effect of floral treatment on pupal parasitism was affected by an interaction with cage treatment $\left(\chi^{2}=12.81, \mathrm{df}=1, P<0.001\right)$; pupae were parasitised at a lower level in buckwheat plots when they

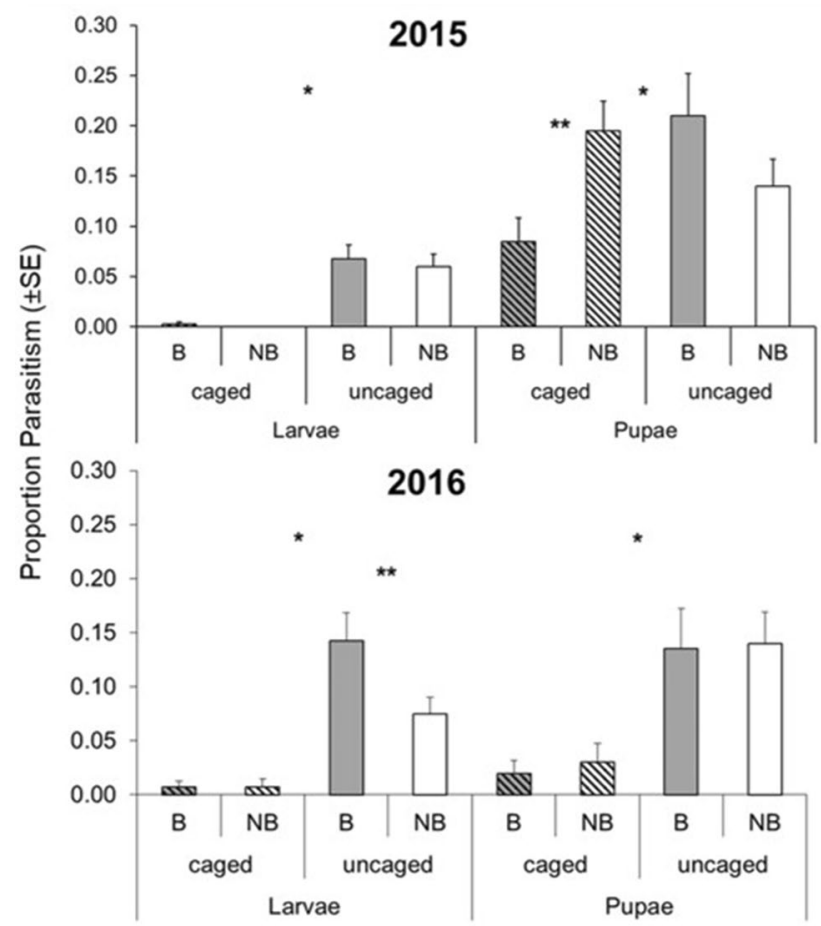

Fig. 2 Proportion of leek moth, Acrolepiopsis assectella, larval and pupal parasitism $( \pm \mathrm{SE})$ in caged and uncaged treatments in buckwheat (B) and no-buckwheat (NB) blocks. (Asterisks (*) indicate significant differences $[P<0.05]$ between treatments as determined by Type II Wald chi-square tests: $*=$ caged and uncaged treatments; $* *=$ buckwheat and no-buckwheat treatments) were on caged leeks $\left(\chi^{2}=9.55, \mathrm{df}=1, P=0.0020\right)$, but there was no effect of floral treatment on pupal parasitism for uncaged leeks $\left(\chi^{2}=0.12, \mathrm{df}=1, P=0.72\right)$. In 2016, however, there was no effect of floral treatment on pupal parasitism $\left(\chi^{2}=0.15, \mathrm{df}=1, P=0.70\right)$; there was greater pupal parasitism on uncaged leeks $\left(\chi^{2}=26.54, \mathrm{df}=1, P<0.0001\right)$.

\section{Parasitism effects on leek moth population growth}

When mortality due to parasitism was removed, the net reproductive rate in both the caged and uncaged treatments increased in all cases except in the 2015 uncaged treatment in both buckwheat and no-buckwheat plots (Table 2). In $2015, R_{0}$ increased by $23.3 \%$ (from 2.92 to 3.60 ) when parasitism was removed in the caged, buckwheat plots and $54.8 \%$ (from 2.21 to 3.42 ) in the caged no-buckwheat plots (see previous paragraph for explanation) (Table 2). The $R_{0}$ in the uncaged buckwheat plots was 1.09 without parasitism, compared to 0 (no reproduction) including parasitism (Table 2). Similarly, in the uncaged no-buckwheat plots, $R_{0}$ was 0.58 without parasitism and 0 including parasitism (Table 2). In $2016, R_{0}$ increased by $4.2 \%$ (from 5.95 to 6.20 ) and $5.6 \%$ (from 5.73 to 6.05 ) in the caged buckwheat and no-buckwheat plots, respectively, in the absence of parasitism (Table 2). The highest increase in $R_{0}$ was measured in the 2016 uncaged treatment in both buckwheat and nobuckwheat plots, which saw increases of 1.36 (256.6\%) and $1.28(246.2 \%)$, respectively when removing the impact of parasitism (Table 2). In the 2015 uncaged buckwheat treatment, and the 2016 uncaged buckwheat and no-buckwheat treatments, the $R_{0}$ increased from that of a declining population to that of a growing population when mortality from parasitism was removed (i.e., $R_{0}>1$ ) (Table 2).

\section{Parasitoid species composition}

The species composition of parasitoids attacking leek moth larvae in buckwheat and no-buckwheat plots differed between years $\left(F_{1.58}=10.68, R^{2}=0.15, P=0.0020\right)$, and to a lesser extent floral treatment $\left(F_{1,58}=3.73, R^{2}=0.052\right.$, $P=0.042)$. There was not a clear effect of the interaction between year and floral treatment on larval parasitoid species composition $\left(F_{1,57}=2.89, R^{2}=0.039, P=0.066\right)$. In 2015, the community of larval parasitoids consisted of a single individual of Gambrus ultimus (Cresson) (Hymenoptera: Ichneumonidae), 15-25\% Scambus spp. (mainly Scambus calobatus (Gravenhorst) (Hymenoptera: Ichneumonidae)), 5\% Bracon sp. (Hymenoptera: Braconidae), and the remaining 70-80\% Habrobracon sp. (Hymenoptera: Braconidae) (Fig. 3-top left). Both G. ultimus and S. calobatus are newly recorded as parasitoids of $A$. assectella. In addition, this is the first report of the genus Habrobracon emerging from a host in the family Glyphipterigidae. In 2016, no 


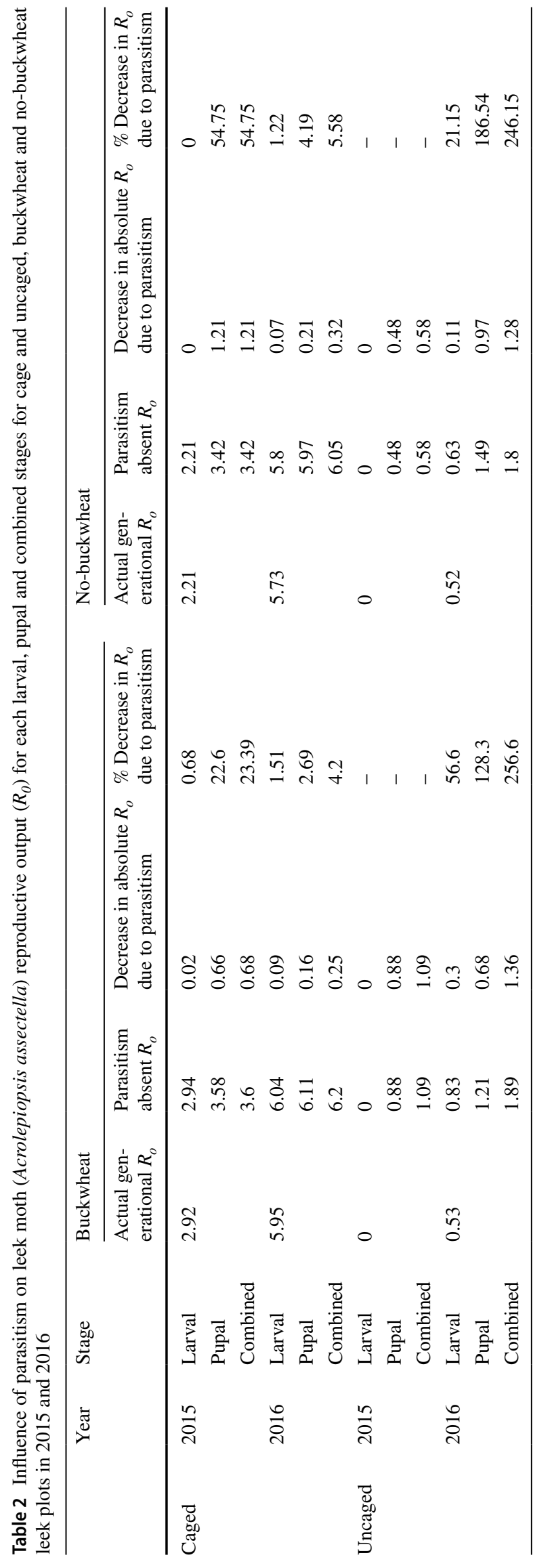

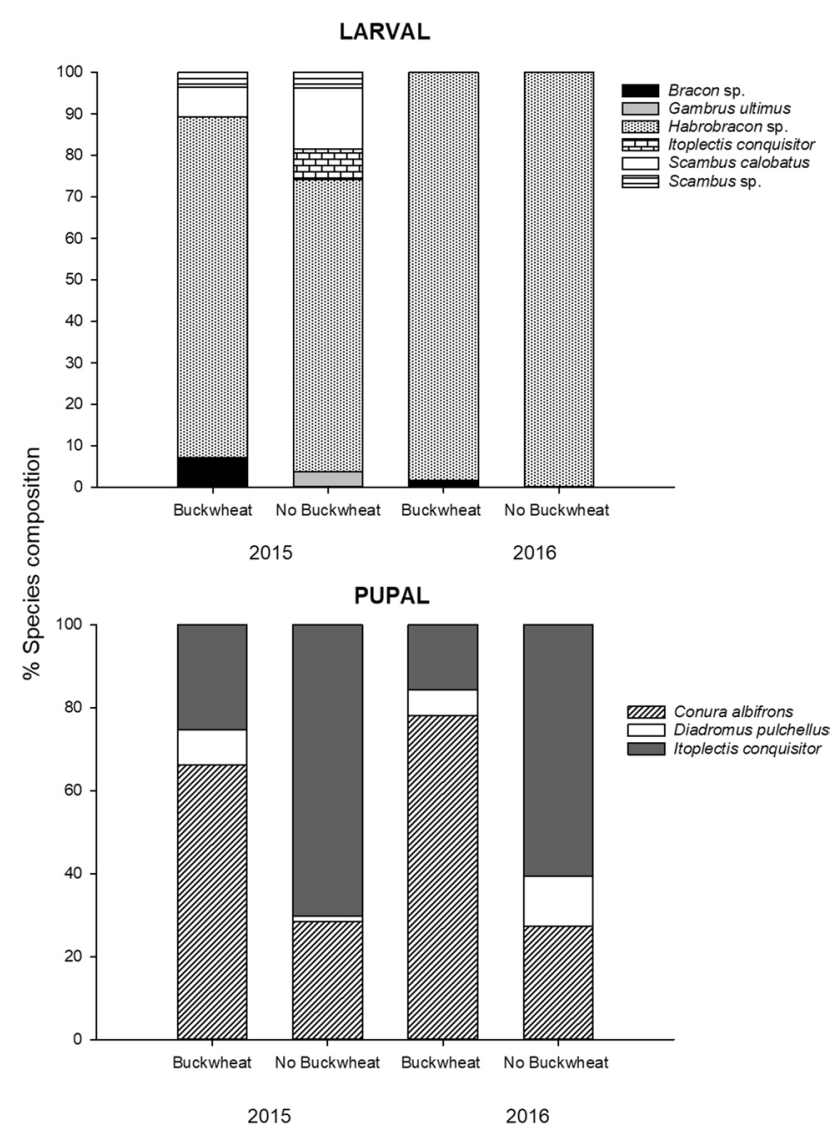

Fig. 3 Parasitoid species composition (\%) from larval and pupal stages of leek moth, Acrolepiopsis assectella, in buckwheat and nobuckwheat leek plots in 2015 and 2016

Gambrus or Scambus spp. were present, about $2 \%$ were Bracon sp. and the remaining larval parasitoids were Habrobracon sp. (Fig. 3-top right). Although the strength of the effect was marginal, the species composition appeared to differ between floral treatments; this was driven by the fact that Bracon sp. was found in the buckwheat plots but not in the no-buckwheat plots in both years.

The pupal parasitoid complex consisted of Itoplectis conquisitor (Say) (Hymenoptera: Ichneumonidae), D. pulchellus, and C. albifrons in buckwheat and no-buckwheat plots. However, the relative prevalence of different parasitoid species consistently differed between buckwheat and no-buckwheat plots $\left(F_{1,82}=16.83, R^{2}=0.17, P<0.001\right)$ but was not affected by year $\left(F_{1,81}=0.46, R^{2}=0.0047, P=0.63\right)$ or an interaction of year and floral treatment $\left(F_{1,80}=0.32\right.$, $\left.R^{2}=0.0033, P=0.74\right)($ Fig. 3). Although the same parasitoid species were present in all year/floral treatment combinations, $C$. albifrons made up more than $60 \%$ of the parasitoids in the buckwheat treatments, whereas I. conquisitor made up more than $60 \%$ of the parasitoids in the no-buckwheat plots. In both 2015 and 2016, the prevalence of D. pulchellus in the caged and uncaged treatments was lower than 10\% (Fig. 3). 


\section{Discussion}

We predicted that adding flowering plants (buckwheat) to a leek field-an environment otherwise mostly devoid of sugar sources-would cause aggregation of nectar-feeding parasitoids and predators, resulting in improved longevity, fecundity, and activity levels of natural enemies (i.e., parasitoids) for an increase in total leek moth mortality, and a reduction in population growth (Suarez et al. 2005; Desouhant 2010). This hypothesis was generally not supported, as stage-specific and total generational mortality in buckwheat and no-buckwheat plots was similar in both years (Fig. 1, Table 1). This was despite the presence of a number of unexpected parasitoid species in our plots, and an apparent effect of buckwheat addition on the relative abundance of the different species (Fig. 3). In the sections below we will discuss how buckwheat addition may have affected (or not) various mortality factors acting throughout the life cycle of the leek moth to produce these results.

\section{Unknown mortality factors}

Comparison of caged versus uncaged plants across treatments in our experiments suggests that predation is likely an important contributor to leek moth mortality. In the absence of exposure to natural enemies, leek moth on caged plants experienced a greater than tenfold increase in estimated net reproductive output $\left(R_{0}\right)$ resulting in much higher generational reproductive growth than that of uncaged plants in the same treatments (Table 2, 2016 data). The effect of cage treatment on mortality was most prominent in the egg stage as the eggs in the caged plants were seemingly better protected from both biotic and abiotic factors than the uncaged plants; however, neonates experienced higher mortality levels in the caged treatments compared to the uncaged treatments (Table 1, Fig. 1). This is not surprising, since abiotic factors such as wind and excessive moisture may have caused the mesh cage to push against the plant, thus creating a physical barrier that the neonate could not overcome while attempting to feed into the leek plant. Both larval and pupal mortality levels were lower in caged treatments compared to uncaged treatments with the exception of the 2016 caged, no-buckwheat treatment which was slightly higher than in the same uncaged treatment. However, again, life-stage-specific mortality was generally not affected by floral treatment. Generational mortality was usually highest in the pupal stage in both years, followed by larval, and generally lowest in the egg stage (Table 1). Results from these life tables differ from those of Jenner et al. (2010) in Europe, who found that neonate mortality was the primary factor influencing population increase or decrease, followed by mortality of larvae, pupae and finally, eggs. In the Jenner et al. (2010) study, however, parasitism was virtually nonexistent and did not contribute to generational mortality as it did in the current study (see below).

Neonate mortality was generally lower in buckwheat plots than no-buckwheat plots. This might be attributed to a reduction in the severity of detrimental abiotic factors (e.g., wind) within the buckwheat plots, which would lessen disturbances on the leek plants compared to more exposed, no-buckwheat plots. After hatching and prior to entering the plant, neonates are vulnerable to abiotic factors and can easily be knocked off the plant (Jenner et al. 2010). In both years, generational mortality was highest in the pupal stage with the exception of the caged, buckwheat and no-buckwheat plots in 2016, which both had highest mortality in the neonate stage (Table 1, Fig. 1).

\section{Parasitism}

We predicted that parasitism would be higher in the buckwheat plots than in the no-buckwheat plots because the increased nectar resources provided by the buckwheat plants would recruit more parasitoids and improve their fitness (see Berndt and Wratten 2005; Lee and Heimpel 2008; Miall et al. 2019). Although there were sometimes significant differences in parasitism between buckwheat and no-buckwheat plots, for example, higher larval parasitism on uncaged, buckwheat + leek plots in 2016 (Fig. 2), these effects were not consistent across all leek moth life stages or between years. This could be due in part to the dilution of any beneficial effect of nectar feeding by immigration of nectar-fed parasitoids from buckwheat plots into no-buckwheat plots, although the true dispersal abilities of the leek moth parasitoids are not known (Steppuhn and Wäckers 2004; Lee et al. 2006; Kishinevsky et al. 2018). Though not performed in this study, an analysis of the gut contents of parasitoids found in the no-buckwheat plots could help determine, in part, the extent of any parasitoid migration. When we performed an a posteriori analysis of whether parasitism in no-buckwheat plots or parasitoid species composition varied with increasing distance from the nearest buckwheat plantings in buckwheat plots, we found no evidence of any trends (Supplementary Material, Appendix A). This suggests that variation in parasitism within no-buckwheat plots could not be explained by relative proximity to buckwheat plots; however, we cannot exclude the possibility that any such "dilution" effect would be obscured by the dispersal range of parasitoids being greater than the maximum distance between no-buckwheat plots and buckwheat plantings.

While we saw minimal effects of our pilot conservation biological control strategy in terms of greater mortality of leek moth with increasing floral resources, results from the 
life-table analysis indicate that increasing overall parasitism within this system is a worthwhile goal, as it greatly reduced estimated leek moth population growth rates, particularly when affecting the pupal stage (Table 2). Based in part on results from previous sugar and nectar resource-provisioning experiments in the greenhouse (Miall et al. 2019), we originally predicted that the addition of buckwheat to leek plots in the field could differentially affect the two main (pupal) parasitoids known from our system, D. pulchellus and $C$. albifrons. In fact, we found that several other parasitoid species including the larval parasitoids Scambus calobatus and Habrobracon sp. (both newly recorded on A. assectella), and the pupal parasitoid Itoplectis conquisitor, played significant, even dominant roles in overall leek moth parasitism in both floral treatments (Fig. 3). Although several of these species had been recovered previously from leek moth, the high abundance of several of them in this study, and their apparent impact on the host, evident from our life-table analysis, was not anticipated. The parasitoid assemblage of both buckwheat and no-buckwheat treatments, in terms of what species were present, was essentially the same between years. However, the differing relative abundance of the pupal parasitoids between the two treatments (Fig. 3) demonstrated that some were likely benefitting from the buckwheat more than others, or that the presence of buckwheat modified the outcome of competitive interactions. For example, the facultative hyperparasitoid $C$. albifrons was significantly more common in the buckwheat plots than in the no-buckwheat plots (Fig. 3), suggesting that $C$. albifrons may have benefited greatly from the constant supply of nectar-producing buckwheat. In contrast, I. conquisitor was more prevalent in the no-buckwheat plots (Fig. 3). Remarkably, the effect of floral treatment on parasitoid species composition was reproducible among years. These results suggest that for leek moth biological control, habitat manipulation as a component of conservation biological control can change the relative abundances of different natural enemies but have basically neutral effects on pest populations. It is important to note here that the influence of flowering buckwheat on the adult stage of leek moth was not measured, and it is unclear if the leek moth could utilise carbohydrates from buckwheat to influence longevity and fecundity, though it is known through preliminary rearing experiments that both leek moth fecundity and longevity are increased when provided access to sucrose upon eclosion.

\section{Conclusions}

Adding floral resources to agricultural systems to favour natural enemies of insect pests is a conservation biological control technique that has been studied extensively. However, changes in pest mortality due to the augmentation or manipulation of natural enemy communities with these strategies usually rely on measurements of percent parasitism and are thus rarely evaluated in the context of mortality occurring throughout the pest's entire life cycle. We addressed this issue by experimentally examining how intercropping affected pest mortality, generational population growth, parasitism levels, and overall parasitoid species composition. Interestingly, we found that it is possible to manipulate the relative abundance of different natural enemies without apparently affecting levels of pest suppression. Based on our results, future studies should focus on understanding which parasitoid species contribute the most to pest suppression, and thus how to manipulate the parasitoid species composition to improve biological control. Understanding the life histories of each member of the parasitoid and hyperparasitoid community may be an important step in designing field plots that effectively cater to their needs. In more general terms, conservation biological control strategies need to address how whole food webs, and not just a few selected species, may be affected by habitat manipulation techniques.

Acknowledgements The authors wish to thank Andrea Brauner, Stephanie Coghlan, Connor Lee, Josh Levy, Tina Dancau and Melanie Lacroix for their assistance in insect and plant culture maintenance and preparation of experimental plots. Andrea Brauner and Christina Thomsen provided valuable comments on earlier versions of the manuscript.

Authors contribution JHM, PKA, NC, and PGM conceived the study and developed the methodology. JHM, PKA, NC, AMRB, GAPG, JLF, and PGM contributed to the writing of the manuscript. JHM conducted experiments and collected the data. PKA and JHM analysed the data and conducted statistical analyses. AMRB, GAPG, and JLF provided parasitoid identifications and critical biological and phenological information pertaining to each species. PGM secured the funding for the research. All authors have read and approved the final article for submission.

Funding This work was supported by funding from Agriculture and Agri-Food Canada.

\section{Compliance with ethical standards}

Conflict of interest The authors declare no conflict of interest for this publication.

Research involving human participants and/or animals No studies with human or animal (vertebrate) participants were performed by any of the authors for this study.

\section{References}

Anderson MJ (2001) A new method for non-parametric multivariate analysis of variance. Austral Ecol 26:32-46

Araj SE, Wratten S, Lister A, Buckley H (2009) Adding floral nectar resources to Improve biological control: potential pitfalls of the fourth trophic level. Basic Appl Ecol 10:554-562 
Baggen LR, Gurr GM (1998) The influence of food on Copidosoma koehleri (Hymenoptera: Encyrtidae), and the use of flowering plants as a habitat management tool to enhance biological control of potato moth, Phthorimaea operculella (Lepidoptera: Gelechiidae). Biol Control 11:9-17

Bellows TS Jr, Van Driesche RG, Elkinton JS (1992) Life-table construction and analysis in the evaluation of natural enemies. Ann Rev Entomol 37:587-612

Bellows TS Jr, Van Driesche RG (1999) Life table construction and analysis for evaluating biological control agents. In: Fisher TW, Bellows TS, Caltagirone LE, Dahlsten DL, Huffaker CB, Gordh G (eds) Handbook of biological control: principles and applications of biological control. Academic Press, New York, New York, pp 199-223

Berndt LA, Wratten SD (2005) Effects of alyssum flowers on the longevity, fecundity, and sex ratio of the leafroller parasitoid Dolichogenidea tasmanica. Biol Control 32:65-69

Berndt LA, Wratten SD, Scarratt SL (2006) The influence of floral resource subsidies on parasitism rates of leafrollers (Lepidoptera: Tortricidae) in New Zealand vineyards. Biol Control 37:50-55

Bowie MH, Wratten SD, White AJ (1995) Agronomy and phenology of "companion plants" of potential for enhancement of insect biological control. NZ J Crop Hortic Sci 23:423-427

Cardinale BJ, Harvey CT, Gross K, Ives AR (2003) Biodiversity and biocontrol: emergent impacts of a multi-enemy assemblage on pest suppression and crop yield in an agroecosystem. Ecol Lett 6:857-865

Desouhant E, Lucchetta P, Giron D, Bernstein C (2010) Feeding activity pattern in a parasitic wasp when foraging in the field. Ecol Res 25:419-428

Hansen JD (1980) The life history and behavior of Spilochalcis albifrons (Hymenoptera: Chalcididae), a parasite of the larch casebearer, Coleophora laricella (Lepidoptera: Coleophoridae). J Kans Entomol Soc 53:553-566

Harcourt DG (1969) The development and use of life tables in the study of natural insect populations. Ann Rev Entomol 14:175-196

Haye T, Mason PG, Dosdall LM, Kuhlmann U (2010) Mortality factors affecting the cabbage seedpod weevil, Ceutorhynchus obstrictus (Marsham), in its area of origin: a life table analysis. Biol Control 54:331-341

Haye T, Abdallah S, Gariepy T, Wyniger D (2014) Phenology, life table analysis and temperature requirements of the invasive brown marmorated stink bug, Halyomorpha halys, in Europe. J Pest Sci $87: 407-418$

Heimpel GE, Jervis MA (2005) Does floral nectar improve biological control by parasitoids. In: Wäckers FL, van Rijn CJ, Bruin J (eds) Plant-provided food for carnivorous insects: a protective mutualism and its applications. Cambridge University Press, Cambridge, United Kingdom, pp 267-304

Jenner WH, Kuhlmann U, Mason PG, Cappuccino N (2010) Comparative life tables of leek moth, Acrolepiopsis assectella (Zeller) (Lepidoptera: Acrolepiidae), in its native range. Bull Entomol Res 100:87-97

Jonsson M, Wratten SD, Robinson KA, Sam SA (2009) The impact of floral resources and omnivory on a four trophic level food web. Bull Entomol Res 99:275-285

Kishinevsky M, Cohen N, Chiel E, Wajnberg E, Keasar T (2018) Sugar feeding of parasitoids in an agroecosystem: effects of community composition, habitat and vegetation. Insect Conserv Diver 11:50-57

Landry JF (2007) Taxonomic review of the leek moth genus Acrolepiopsis (Lepidoptera: Acrolepiidae) in North America. Can Entomol 139:319-353

Langellotto GA, Denno RF (2004) Responses of invertebrate natural enemies to complex-structured habitats: a meta-analytical synthesis. Oecologia 139:1-10
Lee JC, Andow DA, Heimpel GE (2006) Influence of floral resources on sugar feeding and nutrient dynamics of a parasitoid in the field. Ecol Entomol 31:470-480

Lee JC, Heimpel GE (2008) Floral resources impact longevity and oviposition rate of a parasitoid in the field. J Anim Ecol 77:565-572

Leius K (1961) Influence of food on fecundity and longevity of adults of Itoplectis conquisitor (Say) (Hymenoptera: Ichneumonidae). Can Entomol 93:771-780

Letourneau DK, Armbrecht I, Rivera BS, Lerma JM, Carmona EJ, Daza MC, Escobar S, Galindo V, Gutiérrez C, López SD, Mejía JL, Rangel AMC, Rangel JH, Rivera L, Saavedra CA, Torres AM, Trujillo AR (2011) Does plant diversity benefit agroecosystems? A synthetic review. Ecol Appl 21:9-21

Mason PG, Appleby M, Juneja S, Allen J, Landry JF (2010) Biology and development of Acrolepiopsis assectella (Lepidoptera: Acrolepiidae) in eastern Ontario. Can Entomol 142:393-404

Mason PG, Brauner AM, Miall JH, Bennett AMR (2013a) Diadromus pulchellus in North America: field release against leek moth and new characters to distinguish it from Diadromus subtilicornis, a native diamondback moth parasitoid. Biocontrol Sci Technol 23:260-276

Mason PG, Jenner WH, Brauner A, Kuhlmann U, Cappuccino N (2013b) Acrolepiopsis assectella (Zeller), leek moth (Lepidoptera: Acrolepiidae). In: Mason PG, Gillespie DR (eds) Biological control programmes in Canada 2001-2012. CABI Publishers, Croydon, United Kingdom, pp 56-62

Miall JH, Abram PK, Cappuccino N, Mason PG (2014) Potential impact of the native hyperparasitoid Conura albifrons (Hymenoptera: Chalcididae) on the exotic biological control agent Diadromus pulchellus (Hymenoptera: Ichneumonidae). Biocontrol Sci Technol 24:611-624

Miall JH, Abram PK, Cappuccino N, Mason PG (2019) Effects of floral resources on the efficacy of a primary parasitoid and a facultative hyperparasitoid. J Appl Entomol 143:776-786

Peck O (1963) A catalogue of the nearctic Chalcidoidea (Insecta: Hymenoptera). Mem Entomol Soc Can 95:5-1092

Pedersen BS, Mills NJ (2004) Single vs. multiple introduction in biological control: the roles of parasitoid efficiency, antagonism and niche overlap. J Appl Ecol 41:973-984

Possinger AR, Byrne LB, Breen NE (2013) Effect of buckwheat (Fagopyrum esculentum) on soil-phosphorus availability and organic acids. J Plant Nutr Soil Sci 176:16-18

Poveda K, Gómez MI, Martínez E (2008) Diversification practices: their effect on pest regulation and production. Rev Colomb Entomol 34:131-144

R Core Team (2016) R: A language and environment for statistical computing. Version 3.3.2. R Foundation for Statistical Computing. Vienna, Austria

Root RB (1973) Organization of plant-arthropod association in simple and diverse habitats: the fauna of collards (Brassica oleracea). Ecol Monogr 43:95-124

Seto M, Shelton AM (2016) Development and evaluation of degree-day models for Acrolepiopsis assectella (Lepidoptera: Acrolepiidae) based on hosts and flight patterns. J Econ Entomol 109:613-621

Stephens MJ, France CM, Wratten SD, Frampton C (1998) Enhancing biological control of leafrollers (Lepidoptera: Tortricidae) by sowing buckwheat (Fagopyrum esculentum) in an orchard. Biocontrol Sci Technol 8:547-558

Steppuhn A, Wäckers FL (2004) HPLC sugar analysis reveals the nutritional state and the feeding history of parasitoids. Funct Ecol 18:812-819

Suarez RK, Darveau CA, Welch KC, O'Brien DM, Roubik DW, Hochachka PW (2005) Energy metabolism in orchid bee flight muscles: carbohydrate fuels all. J Exp Biol 208:3573-3579 
Tscharntke T, Klein AM, Kruess A, Steffan-Dewenter I, Thies C (2005) Landscape perspectives on agricultural intensification and biodiversity-ecosystem service management. Ecol Lett 8:857-874

Tscharntke T, Bommarco R, Clough Y, Crist TO, Kleijn D, Rand TA, Tylianakis JM, van Nouhuys S, Vidal S (2007) Conservation biological control and enemy diversity on a landscape scale. Biol Control 43:294-309

Tscharntke T, Karp DS, Chaplin-Kramer R, Batáry P, DeClerck F, Gratton C, Hunt L, Ives A, Johnsson M, Larsen A, Martin EA, Martinez-Salinas A, Meehan TD, O'Rourke M, Poveda K, Rosenheim JA, Rusch A, Schellhorn N, Wanger TC, Wratten S, Zhang W (2016) When natural habitat fails to enhance biological pest control-five hypotheses. Biol Conserv 204:449-458

Ueno T (1998) Selective host-feeding on parasitized hosts by the parasitoid Itoplectis naranyae (Hymenoptera: Ichneumonidae) and its implication for biological control. Bull Entomol Res 88:461-466

Van Driesche R, Hoddle M, Center T (2009) Control of pests and weeds by natural enemies: an introduction to biological control. Blackwell Publishing. Malden, Massachusetts, United States, pp 243-247
Vandermeer J (1989) The ecology of intercropping. Cambridge University Press, Cambridge

Weibull AC, Östman Ö, Granqvist $\AA$ (2003) Species richness in agroecosystems: the effect of landscape, habitat and farm management. Biodivers Conserv 12:1335-1355

Wratten SD, Gurr GM, Landis DA, Irvin NA, Berndt LA (2000) Conservation biological control of pests: multi-trophic-level effects. In: Hoddle MS (ed) California Conference on Biological Control II, 11-12 July. Riverside, California, United States, pp 74-80

Yu JZ, Chi H, Chen BH (2013) Comparison of the life tables and predation rates of Harmonia dimidiata (F.) (Coleoptera: Coccinellidae) fed on Aphis gossypii Glover (Hemiptera: Aphididae) at different temperatures. Biol Control 64:1-9

Zemenick AT, Kula RR, Russo L, Tooker J (2019) A network approach reveals parasitoid wasps to be generalized nectar foragers. Arthropod-Plant Interact 13:239-251

Publisher's Note Springer Nature remains neutral with regard to jurisdictional claims in published maps and institutional affiliations. 